\title{
TEORÍA GENERAL DEL CONTROL EN URUGUAY
}

\author{
GENERAL THEORY OF CONTROL IN URUGUAY
}

\author{
Rubén FLORES-DAPKEVICIUS
}

RESUMEN: El control es el poder, jurídicamente regulado, realizado por el órgano de control, sobre el órgano controlado. Es de la esencia del Estado de derecho democrático. El fin de ese control es evitar el abuso de poder, en virtud de la limitación del mismo. Se verifica mediante la contrastación de la actividad puesta en conocimiento y la regularidad jurídica de esa materia controlada. El Tribunal de Cuentas es un órgano de creación constitucional cuya competencia es el control financiero contable, en este supuesto externo a la gestión y sistema orgánico controlado. Nuestro análisis es teniendo en cuenta la rápida accesibilidad, especialmente, de los diversos países ajenos a la realidad uruguaya.

Palabras clave: control, tribunal, cuentas, Estado de derecho, democracia.
ABSTRACT: The control is the power, legally regulated, which is realized by the organ that takes charge of another. It is the essence of the democratic State. The purpose of such control is to prevent abuse of power, by virtue of the limitation of it. Is verified through the contrast of the activity and the regularity of such legal topic under control. The "Tribunal de Cuentas" is a constitutional organ whose jurisdiction is the financial accounting, in this case, outside the organic system under control. Our anaysis is taking into account the rapid accessibility, especially, the various countries outside the Uruguayan reality.

Descriptors: Control, Court, Accounts, the Rule of Law, Democracy. 


\section{INTRODUCCIÓN}

El presente trabajo tiene por motivo el estudio general de la teoría del control para, luego, y con sus luces, analizar el control administrativo competencia del Tribunal de Cuentas de la República Oriental del Uruguay.

\section{Concepto de control}

La teoría general del control es de la esencia del derecho y, especialmente, del Estado de derecho. ${ }^{1}$

Respecto del poder de derecho se plantean las dos cuestiones fundamentales. Éstas son la justificación del poder y su legitimidad. No hay que confundirlas, como se las confunde a menudo. La justificación del poder es un problema filosófico de origen del poder, y la legitimidad es un problema jurídico de transmisión. ${ }^{2}$

Por otra parte, en lo que importa a este trabajo, corresponde señalar que existen diversas etapas en el desarrollo de una tarea o cometido. Sin perjuicio de la multiplicidad de éstos, pueden establecerse reglas generales en el proceso de su desarrollo y cumplimiento. Así, el cometido se desarrollará mediante una planificación, previa, que observe y coordine los medios para su cumplimiento, la ejecución de la tarea y, por último, la que nos convoca, esto es, el control.

El control, que es un fenómeno que limita el poder, permitirá observar la eficacia y la eficiencia en el cumplimiento del cometido, así como su regularidad jurídica, evitando el abuso del poder.

Es una experiencia eterna que todo hombre que tiene poder siente la inclinación de abusar de él, yendo hasta dónde encuentra límites. Para que no se pueda abusar del poder es preciso que el poder frene al poder. $^{3}$

La separación de poderes, entonces, es un principio fundamental para el Estado de derecho público. Surge con meridiana claridad del artículo

1 Flores-Dapkevicius, Rubén, Manual de derecho público, Buenos Aires, Euros Editores, 2007, t. I, p. 288.

2 Hauriou, Maurice, Principios de derecho público y constitucional, Madrid, Reus, 1925, p. 187.

3 Montesquieu, Carlos de Secondat, El espíritu de las leyes, Madrid, Tecnos, 1972, p. 44. 
16 de la Convención del Hombre y el Ciudadano de agosto de 1789. Por el mismo, toda sociedad en la que la garantía de los derechos no esté asegurada ni la separación de poderes determinada, carece de Constitución.

Sólo el poder que controla el poder garantiza la libertad y la justicia, gracias al equilibrio impersonal de los poderes separados, que entre sí se fiscalizan. ${ }^{4}$

Es claro que la forma más acabada de limitar el poder es a través del derecho. ${ }^{5}$

Un sistema es democrático, si y sólo si, existe una separación de poderes bien definida. Además esos poderes deben poder controlarse mutuamente, sin que prevalezca uno sobre otro ni pueda dictar actos en su nombre.

Uno de los fines fundamentales de la Constitución democrática es, precisamente, ese, controlar el poder. Es así que el Estado constitucional se caracteriza por la distribución del poder y al autocontrol que se ejerce por los diversos órganos entre sí. ${ }^{6}$

En el actual desarrollo de la sociedad, los diversos órganos del Estado ejercen, predominantemente, una función jurídica. Esto es, son partícipes de parte del poder etático soberano que es uno solo. De esta forma cada Poder del Estado, entendido como aparato, y los demás órganos estatales, ${ }^{7}$ se controlan mutuamente. Lo expuesto no significa olvidar el control popular soberano.

A los efectos de evitar ese peligro siempre presente, que es inmanente a todo poder, el Estado organizado exige de manera imperativa que el ejercicio del poder público, tanto en interés de los gobernantes como de los destinatarios del poder, sea restringido y limitado. Limitar el poder político quiere decir limitar a los que poseen y ejercen el poder. Un acuerdo de la comunidad sobre una serie de reglas fijas que obligan a los gobernantes, se ha mostrado como el mejor medio para dominar y evitar el abuso del poder político por parte de sus detentadores. El mecanismo de esas reglas que están ya formuladas en un documento formal, la Cons-

4 Mejía Quintana, Óscar, Derecho, legitimidad y democracia deliberativa, Colombia, Temis, 1998, p. 151.

5 Hauriou, Maurice, Derecho público constitucional, España, Reus, 1927, p. 280.

6 Mayer, Otto, Derecho administrativo alemán, Buenos Aires, Depalma, 1982, p. 67.

7 En nuestro país, por ejemplo, el Tribunal de Cuentas, el comisionado parlamentario, etcétera. 
titución, o bien profundamente enraizadas en las costumbres y conciencia nacional, es complejo. ${ }^{8}$

Para nosotros, el control es el poder, jurídicamente regulado, realizado por el órgano de control sobre la competencia del órgano controlado. El mismo puede realizarse dentro y fuera del sistema. Inclusive dentro de un mismo órgano. El fin de ese control es evitar el abuso de poder, en virtud de la limitación del mismo. Se verifica mediante la contrastación de la actividad puesta en conocimiento y la regularidad jurídica de esa materia controlada. El tema es de singular importancia en virtud de que el control es un cometido esencial del Estado y es inherente al Estado de derecho material personalista.

Lo expuesto significa que el control es un juicio lógico. Un análisis esencialmente intelectual, respecto a una determinada actividad, observando si la misma se desarrolla de acuerdo al orden jurídico.

Sus etapas metodológicas o procedimentales son: 1. La recolección de información respecto de la actividad controlada, recibos, comprobantes, etcétera; 2. La contrastación con el marco jurídico dispuesto, y 3. El juicio final.

\section{Caracteres y reglas del control}

Los caracteres fundamentales del control son:

1. Instrumentalidad. El control existe para verificar la regularidad del ejercicio activo de una función o cometido. Es decir, se controla el accionar principal. Por ejemplo si se siguió el procedimiento licitatorio en el supuesto de compra de insumos para industrializar agua potable.

2. Accesoriedad. El control no finaliza con el dictado de una regla de derecho. Sólo se expide un juicio respecto de la actividad controlada. De esta forma el control existe para el cometido principal y no éste para aquél.

3. Inherencia. El control es una característica fundamental, excluyente, del Estado de derecho democrático personalista. Éste, para ser tal, necesita limitar el poder, y esa limitación se ejerce por el con-

8 Loewenstein, Karl, Teoría de la Constitución, Barcelona, Ariel, 1976, p. 14. 
trol de los órganos estatales entre sí, y por el que desarrolla el pueblo soberano.

En lo que respecta a la organización institucional, nuestro país establece en forma inequívoca el principio de separación de poderes en el artículo 82 de la Constitución de 1967 vigente y sus enmiendas parciales. Esta circunstancia afirma y reafirma la inherencia y pertinencia necesaria de la presencia del intercontrol orgánico.

Por otra parte, para que el control pueda desarrollarse, de acuerdo con su finalidad, necesita determinadas reglas. Las reglas del control son:

1. La independencia técnica del órgano controlante. El control no puede existir si no existe esta característica.

2. Imparcialidad del controlante.

3. Colaboración entendida como la que debe brindar el órgano controlado al controlante.

4. Oportunidad. El control no puede entorpecer el funcionamiento del ejercicio de la competencia activa controlada. Por ejemplo la producción de energía eléctrica por la persona estatal competente.

5. Un órgano puede desarrollar diversos controles sobre diversos poderes y órganos del Estado. Eso sucede en Uruguay, Alemania, etcétera.

\section{Clasificaciones}

Existen diversos tipos de control que surgen de cada criterio clasificante. En ese sentido, entonces, a continuación observemos los diferentes controles.

\section{A. Control interno y externo}

Los tipos de control pueden operar dentro de la organización. Es el tipo de control en la organización interna. Es un tipo de control que puede ser horizontal o vertical. Será horizontal cuando los órganos sujetos del proceso de control se encuentren en una misma situación institucional. El supuesto de control interno vertical es el control de tipo jerárquico. 
Es decir, donde existe la jerarquía del controlante y la subordinación del controlado

El ejemplo típico de control interno horizontal se da en el Poder Ejecutivo colegiado. Allí, cada soporte controla a su colega, de igual jerarquía, dentro del mismo órgano.

En el Poder Legislativo nacional este tipo de control interno horizontal se materializa en las competencias diferentes y diferenciantes de los diversos órganos que lo integran. También, y esto importa, en el control natural y obvio que ejerce una cámara legislativa sobre la otra, y viceversa, en el proceso de sanción de las leyes.

El control, además, puede ser fuera del sistema respectivo. Es decir, que opera, de principio, fuera del sistema orgánico por un sistema orgánico ajeno al controlado.

Una regla básica del control que nos convoca es que determinadas tareas puedan realizarse, exclusivamente, si interviene más de un sistema orgánico. Es el supuesto de celebración de tratados internacionales. Esa necesaria participación establece un control de ambos sistemas orgánicos participantes, el Poder Ejecutivo al suscribir y ratificar un tratado y del Poder Legislativo que tiene que aprobarlo.

Lo mismo sucede cuando ambos poderes participan de la elaboración de las leyes, típico control externo horizontal y eventuales primacías según los casos.

En resumen, más simplemente explicado, de acuerdo con la situación institucional del controlante, el control podrá ser interno o externo. Si el órgano controlante pertenece al sistema orgánico controlado será un control interno. Un ejemplo es el control que ejerce la Auditoría Interna de la Nación respecto del Poder Ejecutivo.

El control es externo si el órgano controlante es ajeno al órgano o sistema controlado. Por ejemplo el control que ejerce el Tribunal de Cuentas respecto de toda la administración, con su obvia exclusión. Otro control fundamental es el que realiza el Poder Ejecutivo respecto de las entidades descentralizadas por servicios. Es el control en la descentralización que puede finalizar en el control de la descentralización efectuado por la Cámara de Senadores. ${ }^{9}$

9 Véase el análisis hecho en su oportunidad, en Flores Dapkevicius, Rubén, Constitución de la República Oriental del Uruguay, anotada y concordada, Montevideo, Amalio Fernández, 2004, notas a los artículos 197 y 198. 


\section{B. Control de los habitantes y ciudadanos}

El control ciudadano surge de la acción o recurso directo del ciudadano o habitante. En el presente desarrollo hemos referido, esencialmente, al control de los poderes del Estado. Sin embargo, existe otro tipo de control que es el que nos convoca: el control de las personas del Estado respecto a la actuación de los gobernantes. En ese sentido existen diversos instrumentos jurídicos de control. En primer lugar nuestra Constitución establece el plebiscito que "da vida a (toda) nueva Constitución", artículo $331 .{ }^{10}$

Otro supuesto de control popular lo encontramos en el artículo 191 de la carta que refiere a la publicación periódica de estados que reflejen la vida financiera de los organismos descentralizados.

La carta magna uruguaya establece el recurso de referendum contra las leyes nacionales (artículo 79) y contra los actos legislativos de nuestras circunscripciones territoriales descentralizadas, artículo 304. Estas especies permiten el ejercicio de la democracia directa y son medios de control popular, eficientes y eficaces, cuando se desarrollan contra leyes fundamentales para el colectivo.

La iniciativa popular en materia constitucional y legal es otra forma de control. Ésta es, tal vez, menos directa pero igualmente efectiva respecto a las demás especies, artículos 331 y 79 de la Constitución.

Los recursos administrativos son eficientes en el control de la actividad administrativa, particularmente cuando se presenta el recurso jerárquico en el supuesto de una desconcentración exclusiva.

La elección de los magistrados del bien común puede entenderse como el control final de los ciudadanos respecto de sus mandatados o representantes.

\section{Control de constitucionalidad de las leyes}

La Constitución uruguaya establece la defensa de la supralegalidad constitucional mediante la declaración de inconstitucionalidad de las leyes. Es un tipo de control jurisdiccional, pero su importancia en lo que respecta al ejercicio del habitante, es fundamental.

10 Cagnoni, José Aníbal, Introducción a la teoría del control, Montevideo, Universidad Ltda., 1996, p. 62. 


\section{Control jurisdiccional, administrativo y parlamentario}

De acuerdo con el órgano que ejerce el control, observamos el control jurisdiccional, administrativo o parlamentario. Es un criterio subjetivo, ${ }^{11}$ no formal ni material. En el ejercicio de sus actividades el Estado puede dar motivo a que las personas afectadas deduzcan acciones jurisdiccionales ante el Poder Judicial o Tribunal Constitucional Administrativo. Éste juzga la juridicidad de los actos administrativos definitivos. Si declara la nulidad del acto su efecto puede ser múltiple, como se verá, pero especialmente tiene efecto ex tunc. Por ejemplo un funcionario puede verse lesionado en su derecho al ascenso y luego de agotada la vía administrativa tiene la posibilidad de recurrir a la anulación del acto administrativo. El Poder Judicial entiende en materia de reparatoria patrimonial. Por ejemplo cuando un particular choca contra una obra pública mal señalizada. El control parlamentario, capítulo sustantivo del derecho parlamentario, se realiza, fundamentalmente, a través de los artículos 118 a 121 y 147 y 148 de la carta.

No olvidemos que se denomina derecho parlamentario el estudio profundizado de la porción del derecho constitucional que se aplica al conocimiento de las normas sustantivas y reglamentarias (en sentido amplio para nosotros) del Poder Legislativo. ${ }^{12}$

El control administrativo se realiza por órganos administrativos. Por ejemplo el que efectúa el Tribunal de Cuentas.

De acuerdo con la naturaleza del acto final de contrastación, el control también podrá ser administrativo, parlamentario o jurisdiccional si finaliza en un acto administrativo, legislativo o jurisdiccional. Esto significa que se observa cuál es el acto que expresa el juicio de control.

Si se sigue un proceso judicial será jurisdiccional, y así sucesivamente. En ese sentido observamos el criterio formal para clasificar el control en jurisdiccional, parlamentario y administrativo.

11 Es decir orgánico.

12 Bidegain, Carlos, Curso de derecho constitucional, Buenos Aires, Abeledo Perrot, 2001, p. 65. 


\section{E. Control de legalidad o mérito}

Según el objeto controlado existe el control de legalidad o jurisdicidad y el control de mérito. En el primero se observa la adecuación de la actividad a la regla de derecho. En el control de mérito se observa la oportunidad o conveniencia de la actividad controlada.

\section{F. Control de oficio o a instancia de parte}

De acuerdo a quién puede imponerlo observamos el control de oficio $o$ a instancia de parte.

Es de oficio cuando el órgano de que se trate tiene los poderes jurídicos como para iniciarlo cuando estime oportuno o se lo determine la regla de derecho.

El control es a instancia de parte cuando el legitimado activo es el que puede iniciar el procedimiento. Por ejemplo en el supuesto de interposición de un recurso jerárquico.

\section{G. Control preventivo, concomitante y a posteriori}

Conforme al momento del control existe, también, el control preventivo, el control concomitante y el control a posteriori de la actividad controlada.

El control es preventivo cuando se desarrolla dentro del procedimiento administrativo, que dará lugar al respectivo acto administrativo, antes de su resolución.

El control se entiende concomitante porque se desarrolla mientras se ejecuta la relación principal de cumplimiento del cometido o tarea del órgano controlado.

Por último, el control es a posteriori cuando se desarrolla luego del dictamen del acto principal de cumplimiento del cometido o de su ejecución.

\section{H. Control financiero}

Un control que merece especial atención es el que efectúa el Tribunal de Cuentas. Surge de los artículos 193, 212 y 228 de la carta. Este tipo 
de control es técnico, por oposición al control político que realiza, por ejemplo, el Parlamento. ${ }^{13}$

El tema se analiza seguidamente.

\section{El ombudsman}

Debe recordarse el control que realiza el comisionado parlamentario y el ombudsman. Es un control con forma procedimental administrativa.

\section{J. Control parlamentario sobre el Poder Ejecutivo}

Una de las formas más claras de control parlamentario se produce en el supuesto del nombramiento de los miembros del Poder Ejecutivo. En tal sentido puede observarse el voto de confianza y la censura parlamentaria.

Otros tipos de controles se dan cuando el Parlamento no aprueba un proyecto de ley presentado por el Poder Ejecutivo, en los presupuestos operativos, etcétera.

Asimismo observamos el pedido de datos e informes, llamado a sala $\mathrm{y}$ comisiones de investigación. Es conocido, ampliamente por todos, y especialmente después del caso Nixon, el impeachment estadounidense, el juicio político.

\section{K. Control del Poder Ejecutivo sobre el Parlamento}

En Uruguay este tipo de control se produce, especialmente, en la elaboración de las leyes, mediante el instituto del "veto" u observaciones.

Como se sabe, en nuestro país, el Parlamento es independiente en materia financiera porque el Poder Ejecutivo no interviene en la aprobación del presupuesto de las cámaras, artículo 108 de la Constitución. Sin embargo, la referida disposición exige una mayoría especial que obliga, en la práctica, al control interno de los propios parlamentarios y los diversos partidos políticos que integran el cuerpo.

Un control, ya no jurídico, aunque apoyado indirectamente en las normas de elección, es el que se realiza por el presidente de la República,

13 Flores Dapkevicius, Rubén, op. cit., nota 9, comentario a los referidos artículos. 
líder natural del partido político ganador de las elecciones. Este control lo realiza, previamente, en su influencia en la confección de las listas de los futuros parlamentarios. Luego de la elección, y ya en el ejercicio del cargo, lo realiza con su influencia política y con una siempre posible amenaza, real o imaginaria, dirigida al parlamentario, de ser excluido o relegado en las listas para las próximas elecciones, si no vota la política del primer magistrado. Esa puede ser la realidad constitucional, que puede ser inconveniente, o inmoral, pero que no puede negarse y debe considerarse a esos efectos para el mejoramiento del sistema democrático.

\section{Control politico del Poder Judicial}

Algunos autores entienden que la participación de los tribunales en el proceso político queda confinada a aquellos Estados que prevén el control judicial de la legislación y a los Estados que permiten el control de la administración por los tribunales. Calificar este tipo de control como político, con nuestra formación y de acuerdo a nuestra Constitución, no es del todo acertada. Tal vez la situación pueda ser diversa en sistemas como el estadounidense.

El principio de independencia judicial conduce a la exigencia de que los tribunales ordinarios tengan el monopolio de la administración de justicia. La doctrina y el derecho comparado admiten diversas excepciones.

La judicialización de la política se inicia, especialmente, en la República Federal Alemana que tiende a otorgar al Poder Judicial la posición dominante de árbitro supremo en la dinámica del proceso político. Según la Ley Fundamental de Bonn, el Tribunal Constitucional Federal (Bundesverfassungsgericht) está autorizado a decidir en un proceso judicial sobre los conflictos constitucionales que surjan entre los mismos órganos estatales o los gobernantes. El tema es difícil porque si se otorga el derecho a los tribunales de frustrar una decisión política del Poder Ejecutivo y del Parlamento, se corre el riesgo de que la decisión del Tribunal no sea respetada, o bien que la decisión política del gobierno sea sustituida por un acto judicial que, aunque revestido como jurídico constitucionalmente, no es, en el fondo, sino un acto político. ${ }^{14}$ 
En Uruguay el control del Poder Judicial es un control técnico, esencialmente de juridicidad, nada más, pero nada menos.

\section{Control por exigencia de mayorías especiales}

Este control consiste en la exigencia de mayorías especiales para la protección de minorías o de situaciones especialmente consideradas. Por ejemplo nombramiento de determinados funcionarios. Allí se protege a la minoritaria representación parlamentaria exigiéndose un número especial de adhesiones a los efectos de las designaciones. Ello lleva, necesariamente, a la negociación y a la presencia del partido minoritario, mediante sus representantes políticos, al necesitarse sus votos en las designaciones correspondientes.

\section{El Tribunal de Cuentas}

Las normas constitucionales establecen los principios fundamentales de la organización, poderes jurídicos y competencias del Tribunal de Cuentas.

En la República Oriental del Uruguay el Tribunal de Cuentas es un órgano de creación constitucional, ${ }^{15}$ ejemplo paradigmático de control, en este supuesto externo a la gestión y sistema orgánico controlado.

Es decir, el Tribunal controla la gestión financiera de sistemas a los que no pertenece. Ello es así porque el órgano es extra poder. No integra ningún poder del Estado ni se encuentra subordinado a órgano alguno. Se destaca con énfasis esto porque en la legislación comparada y en la historia del derecho, observamos que el Tribunal dependió, por ejemplo, del Poder Legislativo.

El Tribunal de Cuentas actúa únicamente en ejercicio de la función administrativa. Ello es así en virtud de que, aplicando los diversos criterios de clasificación de las funciones jurídicas del Estado, según la Constitución Uruguaya, los actos que emanan de su competencia tienen el régimen jurídico de los actos administrativos. De ahí que no sea un "tribunal" en el sentido jurisdiccional. En otras legislaciones de derecho comparado sucede algo diverso: “... en la medida que los juicios de cuen-

15 Flores-Dapkevicius, Rubén, Manual de derecho público, cit., nota 1, t. II, p. 388. 
tas son procedimientos que versan sobre cuentas seguidos en el Tribunal de Cuentas, hay que concluir que dichos procedimientos - los juicios de cuentas - son procedimientos judiciales". ${ }^{16}$

El Tribunal de Cuentas no es un poder del Estado porque no le fue atribuida, de principio, el ejercicio de una función jurídica del mismo. ${ }^{17}$ Por tal motivo el órgano ejercerá las funciones que expresamente le asigne la carta y las necesarias para desarrollar sus cometidos, los cuales son de excepción y, en consecuencia, necesitan texto expreso de interpretación estricta que no acepta interpretaciones analógicas o extensivas. Sin perjuicio de ello es un órgano extra poder, lo cual significa que no pertenece o depende de ningún poder del Estado. Esto resulta imprescindible para el correcto e independiente desarrollo de su tarea. En otras legislaciones la situación es diversa. Así, el Tribunal de Cuentas que venía formando parte de la administración pública, ha pasado a depender de las Cortes a partir de la entrada en vigor de su nueva Ley Orgánica, artículo 136 de la Constitución Española. ${ }^{18}$

Más allá de su independencia, como sucede en todos los supuestos de presupuestos operativos aprobados por el sistema establecido en el artículo 220 de la Constitución, el Tribunal de Cuentas no cuenta con autonomía financiera.

Tal situación es un grave problema para el cumplimiento de sus cometidos. El esquema del presupuesto del artículo 220 de la Constitución es el siguiente:

1. El proyecto es presentado por los mismos entes al Poder Ejecutivo.

2. El Ejecutivo puede efectuar la incorporación del mismo al proyecto de presupuesto nacional.

3. El Poder Ejecutivo puede, también, proponer modificaciones.

4. El último paso es la aprobación legislativa mediante la ley nacional de presupuesto quinquenal. En este caso el Parlamento observará el

16 Ballbé Manuel y Franch Marta, Manual de derecho administrativo Marquès Tallers Gràfics, España, Girona, 2002, p. 249.

17 La afirmación no es menor.

18 González Navarro, Francisco, Derecho administrativo español, España, Aranzadi, Civitas Ediciones, 1995, p. 443. 
presupuesto original y sus modificaciones. Las modificaciones del Poder Ejecutivo pueden ser determinantes.

\section{Composición del órgano}

De acuerdo con el artículo 208 de la Constitución, el Tribunal de Cuentas se compone por siete miembros que deberán reunir las mismas calidades exigidas para ser senador. Esto es, ciudadanía natural en ejercicio o legal con siete años de ejercicio, y en ambos casos 30 años de edad cumplidos.

Son designados por la Asamblea General por dos tercios de votos del total de sus componentes. Sus miembros cesan cuando la Asamblea General efectúe los nombramientos para el nuevo periodo.

De no existir nombramiento se produce su continuación. La mayoría establecida para la designación permite la coparticipación de los partidos políticos en el gobierno. Especialmente de las minorías que tienen el deber, y el derecho, de control sobre quienes efectivamente toman las decisiones. Esto es, la mayoría gobernante.

Rigen a su respecto las incompatibilidades establecidas en los artículos 122,123 y 125 de la Constitución.

Las incompatibilidades refieren a la opción que debe efectuar un funcionario de serlo en determinado cargo, en virtud de la posibilidad de ejercer otro.

El artículo 122 de la Constitución establece expresamente que los legisladores nacionales después de incorporados a sus respectivas cámaras, no podrán recibir empleos rentados de los poderes del Estado, de los gobiernos departamentales, de los entes autónomos, de los servicios descentralizados o de cualquier otro órgano público.

Tampoco pueden prestar servicios retribuidos por ellos en cualquier forma, sin consentimiento de la Cámara a la que pertenezcan. La violación de la incompatibilidad es sancionada con la vacante de su representación en el acto de recibir el empleo o de prestar el servicio.

La incompatibilidad que se comenta se aplica a los miembros del Tribunal de Cuentas en lo pertinente, artículo 125 de la carta.

El referido artículo 122 establece otra incompatibilidad fundamental, dejando abierta la opción para que los presuntamente mejores ejerzan los cargos que estimen convenientes, en beneficio de la nación. De esta 
forma, cuando un senador sea convocado para ejercer temporalmente la Presidencia de la República, y cuando los senadores y los representantes sean llamados a desempeñar ministerios o subsecretarías de Estado, quedarán suspendidos en sus funciones legislativas, sustituyéndoseles, mientras dure la suspensión, por el suplente correspondiente.

Las normas se aplican por renvío, en lo pertinente, a los miembros del órgano que nos convoca. Es entonces que un miembro del Tribunal de Cuentas no puede ser, concomitantemente, senador, representante, ministro, etcétera.

Las prohibiciones, que son obligaciones de no hacer, se establecen en el artículo 124 de la Constitución. De esta forma, los ministros del Tribunal no pueden, durante su mandato:

a) intervenir como directores, administradores o empleados en empresas que contraten obras o suministros con el Estado, gobiernos departamentales, entes autónomos, servicios descentralizados o cualquier otro órgano público;

b) tramitar o dirigir asuntos de terceros ante la administración central, gobiernos departamentales, entes autónomos y servicios descentralizados. El incumplimiento de la norma trae aparejada la pérdida inmediata del cargo.

Las prohibiciones legisladas son fundamentales para el ejercicio correcto de la función pública y el servicio al público desterrando posibles prácticas improcedentes.

Las incompatibilidades y prohibiciones están abiertas a la voluntad del legislador. Es decir que, de acuerdo con el artículo 126 de la Constitución, existe la posibilidad de reglamentación de las incompatibilidades y prohibiciones, pudiendo establecer otras, así como extenderlas a los integrantes de órganos diversos. Tratándose de prohibiciones e incompatibilidades deben establecerse por ley. En este caso aprobadas por mayoría absoluta de votos del total de componentes de cada Cámara.

Por último los miembros del Tribunal pueden ser reelectos y deben tener, cada uno, tres suplentes para los casos de vacancia, impedimento temporal o licencia de los titulares. 


\section{Estatuto de sus miembros}

Conforme al artículo 77 numeral 4 de la Constitución, los ministros del Tribunal deben abstenerse de formar parte de comisiones o clubes políticos, de suscribir manifiestos de partido, ejecutar cualquier acto público o privado de carácter político, salvo el voto. La violación de la norma se castiga con destitución e inhabilitación de dos a diez años para ocupar cualquier empleo público.

El artículo 209 de la carta establece que los miembros del Tribunal de Cuentas son responsables, ante la Asamblea General en reunión de ambas cámaras, por el fiel y exacto cumplimiento de sus funciones.

La Asamblea General podrá destituirlos en caso de ineptitud, omisión o delito, mediando la conformidad de dos tercios de votos del total de sus componentes.

Asimismo, los miembros del Tribunal pueden ser sujetos a juicio político. No tienen otro privilegio especial que los proteja en el desempeño de sus cargos como los poseen los legisladores, ministros o el presidente de la República.

El estatuto de sus funcionarios se aprueba de conformidad con el artículo 59 de la carta. Esto es por ley nacional. ${ }^{19}$

\section{Competencias}

Las principales competencias del Tribunal de Cuentas surgen de lo dispuesto en el artículo 211 de la Constitución. Así, al órgano compete:

a) dictaminar e informar en materia de presupuestos. En tal sentido deben observarse los artículos 214, 220, 221, 222, 229 de la Constitución que refieren específicamente al tema, y que no pueden analizarse, en este momento, por razones de espacio;

b) intervenir preventivamente en los gastos y los pagos, conforme a las normas reguladoras correspondientes y al sólo efecto de certificar su legalidad, haciendo, en su caso, las observaciones correspondientes.

Nos encontramos en el supuesto del control preventivo a la toma de la decisión final y ejecución de la misma. El mismo se desarrolla dentro del procedimiento administrativo que dará lugar al respectivo acto administrativo, antes de su resolución. Sin embargo, el ordenador respectivo

19 Flores Dapkevicius, Rubén, op. cit., nota 10, comentario al artículo respectivo. 
puede insistir y tomar la decisión correspondiente, considerada ilegal por el órgano de control. En ese caso lo comunicará al Tribunal sin perjuicio de dar cumplimiento a lo dispuesto. Si el Tribunal de Cuentas, a su vez, mantuviera sus observaciones, dará noticia circunstanciada a la Asamblea General, o a quien haga sus veces, a sus efectos.

Esos efectos no tienen sanción jurídica relevante. Tal situación debe modificarse logrando un justo equilibrio entre el órgano de administración activa, que lleva a la práctica la satisfacción de los cometidos estatales, y el Tribunal de Cuentas.

Lo expuesto significa que si bien deben concederse mayores poderes al Tribunal, o sanciones a la actuación en contra de sus dictámenes, esas medidas no pueden entorpecer el ejercicio de las competencias de los órganos controlados. De otra forma sería crear un superórgano de control, equilibrio y mesura en la distribución del poder. Estas características guardarían de los abusos contra el pueblo y serían un blindaje para proteger al Estado de derecho frente a la actitud de iluminados.

En los gobiernos departamentales, entes autónomos y servicios descentralizados, el cometido que estamos comentando puede ser ejercido con las mismas consecuencias, por intermedio de los respectivos contadores o funcionarios que hagan sus veces. Éstos actuarán en tales cometidos bajo la superintendencia del Tribunal de Cuentas, con sujeción a lo que disponga la ley, la cual podrá hacer extensiva esta regla a otros servicios públicos con administración de fondos. De este literal surge la denominada jerarquía múltiple de más de un jerarca y sistema orgánico, así como la certificación por motivo de legalidad. ${ }^{20}$ Es decir, no se analiza la conveniencia, oportunidad o mérito.

Por otra parte, observamos en esta disposición la posible actuación directa del Tribunal o la actuación por los contadores que menciona. La actuación directa se establece por ley y obedece a determinados montos. De principio, montos que obliguen la licitación pública.

c) Dictaminar e informar respecto de la rendición de cuentas y gestiones de todos los órganos del Estado, inclusive gobiernos departamentales, entes autónomos y servicios descentralizados, cualquiera sea su naturaleza, así como en cuanto a las acciones correspondientes en caso

20 La jerarquía es múltiple porque el contador designado pertenece a la administración controlada. Por ello responde a su jerarca, en el área específica de su competencia, y al Tribunal de Cuentas cuando ejerce el cometido delegado por este órgano. 
de responsabilidad, exponiendo las consideraciones y observaciones pertinentes. La hipótesis refiere el control a posteriori.

d) Presentar a la Asamblea General la memoria anual relativa a la rendición de cuentas establecida en el apartado anterior.

e) Intervenir en todo lo relativo a la gestión financiera de los órganos del Estado, gobiernos departamentales, entes autónomos y servicios descentralizados. Asimismo, debe denunciar ante el órgano competente todas las irregularidades en el manejo de fondos públicos e infracciones a las leyes de presupuesto y contabilidad.

f) Dictar las ordenanzas de contabilidad, mismas que tendrán fuerza obligatoria para todos los órganos del Estado, gobiernos departamentales, entes autónomos y servicios descentralizados, cualquiera que sea su naturaleza.

g) Proyectar sus presupuestos que elevará al Poder Ejecutivo, para ser incluidos en los presupuestos respectivos. El Poder Ejecutivo, con las modificaciones que considere del caso, los elevará al Poder Legislativo, estándose a su resolución. El presupuesto es regulado en el artículo 220 de la Constitución, analizado recientemente.

De acuerdo con el artículo 210 de la Constitución Nacional, el Tribunal de Cuentas actúa con autonomía funcional. La referida disposición establece la competencia abierta del Tribunal a lo que disponga la ley. En tal sentido es órgano de consulta respecto a la materia de su competencia.

El Tribunal de Cuentas ejerce, asimismo, superintendencia en todo lo que corresponda a sus cometidos y con sujeción a lo que establece su Ley Orgánica, sobre todas las oficinas de contabilidad, recaudación y pagos del Estado, gobiernos departamentales, entes autónomos y servicios descentralizados, cualquiera que sea su naturaleza, pudiendo proponer, a quien corresponda, las reformas que creyere convenientes. Lo expuesto surge del artículo 212 de la carta. ${ }^{21}$

\section{CONCLUSIONES}

1. La teoría general del control es de la esencia del derecho y, especialmente, del Estado de derecho.

21 Flores Dapkevicius, Rubén, op. cit., nota 9, comentarios al referido artículo. 
2. Respecto del poder de derecho se plantean las dos cuestiones capitales de la justificación del poder y de su legitimidad.

3. Las anteriores ideas introductorias nos conducen al estudio del control del poder.

4. Existen diversas etapas en el desarrollo de una tarea o cometido. Sin perjuicio de la multiplicidad de éstos pueden establecerse reglas generales en el proceso de su desarrollo y cumplimiento.

5. Así, el cometido se desarrollará mediante una planificación previa que observe y coordine los medios para su cumplimiento, la ejecución de la tarea y, por último, la que nos convoca, esto es, el control.

6. El control, que es un fenómeno que limita el poder, permitirá observar la eficacia y eficiencia en el cumplimiento del cometido, además de su regularidad jurídica, evitando el abuso del poder.

7. Es una experiencia eterna que todo hombre que tiene poder siente la inclinación de abusar de él, yendo hasta donde encuentra límites. Para que no se pueda abusar del poder es preciso que el poder frene al poder.

8. La separación de poderes, entonces, es un principio fundamental para el Estado de derecho material y permite el control de los diversos órganos del Estado.

9. El Estado constitucional se caracteriza por la distribución del poder y el autocontrol que se ejerce por los diversos órganos entre sí.

10. El control es el poder, jurídicamente regulado, realizado por el órgano de control, sobre la competencia del órgano controlado.

11. El control es un juicio lógico. Un análisis esencialmente intelectual, respecto a una determinada actividad, observando si la misma se desarrolla de acuerdo con el orden jurídico y, eventualmente, a la buena administración.

12. Los caracteres fundamentales del control son: la instrumentalidad, la accesoriedad y la inherencia.

13. Las reglas del control son: 1. Independencia técnica del órgano controlante; 2. Imparcialidad del controlante; 3. Colaboración, y 4. Oportunidad.

14. Los tipos de control pueden operar dentro de la organización. Es el tipo de control en la organización interna. Es un control que puede ser horizontal o vertical. 
15. El control ciudadano es el que surge de la acción o recurso directo del ciudadano o habitante. Así, el recurso de referendum, la iniciativa popular, la elección de los magistrados del bien común, etcétera.

16. De acuerdo con el órgano que ejerce el control, observamos el control jurisdiccional, administrativo o parlamentario.

17. Formalmente, es decir según el procedimiento de control, encontramos, también, el control jurisdiccional, administrativo o parlamentario.

18. Puede observarse el control jurisdiccional, el administrativo o el parlamentario si analizamos el contenido final del acto de control.

19. La Constitución uruguaya establece la defensa de la supralegalidad constitucional mediante la declaración de inconstitucionalidad de las leyes.

20. Según el objeto controlado, existe el control de legalidad o juridicidad y el control de mérito. En el primero se observa la adecuación de la actividad a la regla de derecho. En el control de mérito se observa la oportunidad o conveniencia de la actividad controlada.

21. De acuerdo con quien puede imponerlo, observamos el control de oficio o a instancia de parte.

22. Según el momento del control existe, también, el control preventivo, el concomitante y el a posteriori de la actividad controlada.

23. Un control que merece especial atención es el que efectúa el Tribunal de Cuentas. Surge de los artículos 193, 212 y 228. Este tipo de control es técnico, por oposición al control político que realiza, por ejemplo, el Parlamento.

24. Una de las formas más claras de control parlamentario sobre el Poder Ejecutivo se produce en el supuesto de nombramiento de sus miembros no elegidos directamente por el pueblo.

25. Otro tipo de controles parlamentarios se dan cuando el Parlamento no aprueba un proyecto de ley presentado por el Poder Ejecutivo y en los presupuestos operativos. Asimismo, observamos el pedido de datos e informes, llamado a sala, comisiones de investigación y el juicio político.

26. El control de Poder Ejecutivo sobre el Legislativo se produce, especialmente, en la elaboración de las leyes, mediante el instituto del "veto" u observaciones. 
27. El control por mayorías consiste en la exigencia de mayorías especiales de votos para la protección de minorías o de situaciones especialmente consideradas.

28. Las normas constitucionales establecen los principios fundamentales de la organización, poderes jurídicos y competencias del Tribunal de Cuentas.

29. En la República Oriental del Uruguay, el Tribunal de Cuentas es un órgano de creación constitucional, ${ }^{22}$ ejemplo paradigmático de control, en este supuesto externo a la gestión y sistema orgánico controlado. Ello sin perjuicio de su autocontrol por medio de sus integrantes.

30. El Tribunal controla la gestión financiera de sistemas a los que no pertenece.

31. Como órgano extra poder no integra ningún poder del Estado ni se encuentra subordinado a órgano alguno.

32. El Tribunal de Cuentas no es un poder del Estado porque no le fue atribuido, de principio, el ejercicio de una función jurídica del mismo.

33. Por lo expuesto en el numeral que precede, sus cometidos son de excepción y, por ello, necesitan texto expreso de interpretación estricta que no acepta interpretaciones analógicas o extensivas.

34. En nuestro país el Tribunal actúa únicamente en ejercicio de función administrativa.

35. El nombre "Tribunal" es únicamente un apelativo si se lo considera desde el punto de vista del ejercicio de función jurisdiccional.

36. Más allá de su independencia total, como sucede en todos los supuestos de presupuestos operativos aprobados por el sistema establecido en el artículo 220 de la Constitución, el Tribunal de Cuentas no cuenta con autonomía financiera.

37. De acuerdo con el artículo 208 de la Constitución, el Tribunal de Cuentas se compone por siete miembros que deberán reunir las mismas calidades exigidas para ser senador.

38. Sus integrantes son designados, y cesan, por el voto de dos tercios del total de componentes de la Asamblea General.

39. La mayoría establecida para la designación permite la coparticipación de los partidos políticos en el gobierno.

22 Flores-Dapkevicius, op. cit., nota 1, p. 88. 
40. Los miembros del Tribunal están sujetos a las incompatibilidades establecidas en los artículos 122, 123 y 125 de la Constitución Nacional.

41. Las prohibiciones a que están sujetos sus soportes se establecen en el artículo 124 de la Constitución.

42. De acuerdo con el artículo 77 numeral 4 de la Constitución, los ministros del Tribunal deben abstenerse de formar parte de comisiones o clubes políticos, suscribir manifiestos de partido, ejecutar cualquier acto público o privado de carácter político, salvo el voto.

42. El artículo 209 de la carta establece que los miembros del Tribunal de Cuentas son responsables, ante la Asamblea General en reunión de ambas cámaras, por el fiel y exacto cumplimiento de sus funciones.

43. La Asamblea General podrá destituirlos, en caso de ineptitud, omisión o delito, mediando la conformidad de dos tercios de votos del total de sus componentes.

44. Asimismo, los miembros del Tribunal pueden ser sujetos a juicio político.

45. Las principales competencias del Tribunal de Cuentas surgen de lo dispuesto en el artículo 211 de la Constitución.

\section{BIBLIOGRAFÍA}

ARAGÓN Manuel, Constitución y control del poder, Ciudad Argentina, 1996.

BALlBÉ, Manuel y FrAnCH, Marta, Manual de derecho administrativo, Girona, Marquès Tallers Gràfics, 2002.

BIDEgain, Carlos, Curso de derecho constitucional, Buenos Aires, Abeledo Perrot, 2001.

Biscaretti Di RUfFia, Paolo, Derecho constitucional, Madrid, Tecnos, 1973.

CAGNONI, José Aníbal, Introducción a la teoría del control, Montevideo Universidad Ltda., 1996.

Dromi, Roberto, Derecho administrativo, Buenos Aires, 1997.

EsteVA GAliCCHIO, Eduardo, Lecciones de derecho constitucional, Montevideo, RUDCP Editor, 1992.

FiX-ZAmudio, Héctor, Juicio de amparo, México Porrúa, 1964. 
Flores-Dapkevicius, Rubén, Constitución de la República Oriental del Uruguay, anotada y concordada, Montevideo, Amalio Fernández, 2004.

, Manual de derecho público, Buenos Aires, Euros Editores, 2007, 2 ts.

GonZÁlez NAVARro, Francisco, Derecho administrativo español, España, Aranzadi, Civitas Ediciones, 1995.

GonzÁlez CAlderón, Juan A., Curso de derecho constitucional, Buenos Aires, 1943.

Gordillo, Agustín A., Tratado de derecho administrativo, Buenos Aires, Macchi, 1975.

Gros EsPIELl, Héctor, Habeas Corpus en el poder y su control, Montevideo, UCUDAL, 1994.

HaURIOU, Maurice, Derecho público constitucional, Madrid, Reus, 1927.

—. Principios de derecho público y constitucional, Madrid, Reus, 1925.

Jiménez de ArechagA, Justino, La Constitución Nacional, Montevideo, Cámara de Senadores, 1998.

Loewenstein, Karl, Teoría de la Constitución, España, Ariel, 1976.

MARIENHOFF, Miguel, Tratado de derecho administrativo, Buenos Aires, Abeledo Perrot, 1975.

MAYER, Otto, Derecho administrativo alemán, Buenos Aires, Depalma, 1982.

MeJía QuinTana, Óscar, Derecho, legitimidad y democracia deliberativa, Colombia, Temis, 1998.

Montesquieu, Carlos de Secondat, El espíritu de las leyes, Madrid, Tecnos.

Morell OCAÑA, Luis, Curso de derecho administrativo, España, Aranzadi, 1999.

TOFFlER, Alvin, El cambio del poder, España, Plaza \& Janés, 1994. 